\title{
SÉCULOS SEM FIM: CRÔNICAS DO CENTENÁRIO DE CANUDOS
}

\author{
Benito Martinez Rodriguez ${ }^{* *}$
}

Pelos nossos olhos passara a impressão visual da Posteridade.

(Euclides da Cunha, comentando a visita de um jovem

ao leito de morte de Machado de Assis)

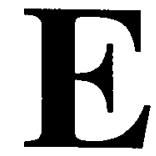

m 14 de fevereiro de 1897, quando já se preparava a expedição militar contra Canudos que teria o comando de Moreira César, Machado de

* Este texto é resultado de minha participação nos seminários da disciplina "Texto e História em Os sertīes, de Euclides da Cunha", no programa de pós-graduação em Letras da Faculdade de Filosofia, Letras e Ciências Humanas da Universidade de São Paulo, sob a coordenação do professor Roberto Ventura durante o segundo semestre de 1993. Sua versão original foi apresentada aos colegas de disciplina e ao coordenador, que com suas críticas e sugestōes ajudaram a minorar-lhe as insuficiências. Agradeço essa generosa contribuição do professor Ventura e de meus companheiros de então.

** Universidade Federal do Paraná. 
Assis publicava uma crônica ${ }^{l}$ na qual se combinavam três temas, à primeira vista, inteiramente díspares: os acontecimentos recentes no interior da Bahia, o lançamento do volume de contos Sertão, de Coelho Neto, e o centenário do surgimento do "chapéu alto", que ainda hoje conhecemos como cartola. Ali podemos ler a seguinte especulação:

Um dia, anos depois de extinta a seita e a gente dos Canudos, Coelho Neto, contador das cousas do sertão, talvez nos dê algum quadro daquela vida, fazendo-se cronista imaginoso e magnífico deste episódio que não tem nada fim-de-século [...] Outro Coelho Neto, se tiver igual talento, pode dar-nos daqui a um século um capítulo interessante, estudando o fervor dos bárbaros e a preguiça dos civilizados, que os deixaram crescer tanto, quando era mais fácil tê-los dissolvido com uma patrulha, desde que 0 simples frade não fez nada. Quem sabe? Talvez então algum devoto, relíquia dos Canudos, celebre o centenário (413 e 416)

O escritor não podia imaginar então que proporções o episódio comentado viria a alcançar, tampouco a extensão de seu significado para o futuro do país. Menos ainda, que um "outro Coelho Neto" não demoraria muitos anos, ou mesmo meses, a aparecer. De fato, exatos trinta dias após a publicação do texto de Machado de Assis, Euclides da Cunha assinava na imprensa paulista o primeiro dos dois artigos sobre os episódios do sertão baiano que precederam sua viagem para acompanhar as etapas finais dos combates como jornalista correspondente.

Publicados com quatro meses de intervalo, ambos sob o mesmo título, "A nossa Vendéia", representam a primeira intervenção pública de maior alcance de Euclides da Cunha sobre a questão de Canudos. O intervalo decorrido entre as publicações corresponde a um período particularmente crítico do conflito, no qual se ingressaria a partir do desastre militar da expedição Moreira

1 ASSIS, J. M. Machado de. A Semana (1895-1900). Rio de Janeiro, W. M. Jackson, 1955 (Obras Completas de ... ; v. 28), p. 412-18. Os números entre parênteses ao final desta, e de todas as demais citaçōes, remetem à paginação nas fontes.

2 Os textos serão citados conforme sua edição em CUNHA, Euclides da. Canudos (Diärio de uuna expedição). Rio de Janeiro: José Olympio, 1939 (Coleção Documentos Brasileiros, 16), p. 161-176, apenas atualizada a grafia. Os artigos foram publicados no jornal $O$ Estado de $S$. Paulo em 14 de março de 1897 e 17 de julho do mesmo ano. 
César. Essa etapa estendeu-se pelos quatro meses seguintes, alcançando seu ápice nas primeiras semanas de combate da quarta expedição, do final de junho até princípios de agosto, quando duas colunas do Exército brasileiro se viram na paradoxal situação de "sitiantes sitiadas" do arraial conselheirista. ${ }^{3}$

Até a época da publicação do segundo artigo, contudo, as notícias que chegavam à capital do país não davam conta, em detalhe, das extraordinárias dificuldades enfrentadas pelas tropas na operação. Parte considerável dessas adversidades, por sinal, se originavam na inadequação das estratégias utilizadas pelo comando às condições do cenário dos combates. Para não mencionar os casos de absoluta incompetência dos oficiais responsáveis na condução das tropas. ${ }^{4} \mathrm{O}$ noticiário da capital e das grandes cidades ainda não começara a publicar os relatos de seus correspondentes no local dos combates. A cobertura jornalística do conflito vinha alternando depoimentos cuidadosos e acurados, como as informações biográficas sobre Antonio Conselheiro oferecidas por João Brígido, com notícias as mais disparatadas, como a história do "jagunço" que teria viajado durante 25 dias da região do conflito até a capital, para "falar ao Sr. Presidente da República, a quem pretendia fazer comunicaçōes importantes". 5

Destoando, em certa medida, do clima geral da imprensa em ambos os momentos ${ }^{6}$, os dois artigos de Euclides da Cunha põem em relevo, cada um a

3 A imagem é utilizada pelo próprio Euclides da Cunha n'Os sertīes. Edição crítica preparada por Walnice Nogueira Galvão. São Paulo, Brasiliense, 1985, p. 456.

4 As matérias de Manuel Benício, correspondente do Jornal do Commercio, são talvez. a melhor análise crítica dos equívocos cometidos durante as primeiras semanas das operações da expedição comandada pelo general Artur Oscar. Suas reportagens, produzidas durante o período mais crítico dos combates da quarta expedição, detalhadas até onde era possivel para um membro da tropa, subordinado às autoridades militares. Revelam excepcional lucidez, não deixando jamais de refletir adınirável objetividade e equilíbrio. No final do mês julho, o jomalista foi "convidado a se retirar [da área de combate] por dar [em suas reportagens] informaçōes julgadas [pelas autoridades] inconvenientes". Ver GALVĀO, Walnice Nogueira. No calor da hora: A Guerra de Camudos nos jornais, 4." expedição. São Paulo: Ática, 1974 (Ensaios, 1), p. 112 e seguintes.

5 GALVĀO, op. cit., p. 61-62.

6 Em meio a um clima de grande exaltação das tendências jacobinas, que resultou no empastelamento de diversos órgãos da imprensa monarquista, o primeiro artigo de Euclides da Cunha, republicano convicto, é marcado por grande moderação e otimismo quanto à vitória final das forças republicanas. $O$ segundo texto, por sua vez, é publicado na véspera da sangrenta ofensiva de 18 de julho, que conduziu ao cerco efetivo do arraial, mas ao preço de expressivas baixas nas fileiras governistas. Vale lembrar ainda que no dia 18 de julho sairia n' $O$ Pais a primeira matéria sobre a suposta "correspondência monarquista" de Canudos, que agitaria o noticiário durante várias semanas. Uma vez mais, nesse clima de exasperação, boatos e pressões por um desfecho rápido para 
seu modo, uma percepção dos acontecimentos que antecipa, talvez de modo mais agudo do que possa parecer à primeira vista, aspectos fundamentais de $O s$ sertões. Não se pretende sustentar aqui a idéia de que uma "virada de opinião" do autor face aos acontecimentos jamais tenha ocorrido. O próprio Euclides é o primeiro a se referir à questão no corpo de seu trabalho ${ }^{7}$. O propósito aqui é ressaltar o caráter desde sempre ambíguo e dividido das interpretações do ensaísta. Sob esse aspecto, a leitura dos artigos oferece uma oportunidade para a reflexão em torno dos modos de construção do texto euclidiano, bem como de seus pontos de vista em face do conflito.

\section{O país ainda por (d)escrever}

As nossas melhores cartas, enfeixando informes escassos, lá [Canudos e suas cercanias] têm um claro expressivo, um hiato, Terra Jgnota, em que se aventura o rabisco de um rio problemático ou a idealização de uma corda de serras.

(Os sertĩes)

Produzido sob o impacto de um significativo revés militar do exército republicano, é surpreendente, à primeira vista, que o primeiro artigo de Euclides da Cunha não faça qualquer alusão direta ao acontecido. De fato, detendo-se longamente na discussão do cenário natural onde se realizavam os combates, baseando-se inteiramente em informações de segunda mão, Euclides não alude ao episódio do fracasso da expedição Moreira César em momento algum do texto. A opção em tomar como ponto de partida de seu esforço interpretativo o exame do cenário físico do sertão baiano, fórmula que alcançará a versão final

o conflito, o trabalho de Euclides da Cunha timbra em defender uma ação perseverante e paciente.

7 Na abertura do item IV dos preliminares de "A luta", o autor desenvolve, com ressalvas, o paralelo entre a rebelião na Vendéia e o episódio de Canudos. Op. cit., p. 282. 
d'Os sertões, domina quase todo o trabalho. Cerca de três quartos do artigo discorrem sobre "as condições geognósticas" do território de Canudos.

As referências utilizadas vão de autores como o brasileiro quase seu contemporâneo, José C. de Carvalho, até naturalistas estrangeiros dos princípios do século XIX, Martius e Saint-Hilaire. Em suas considerações a respeito das causas da seca, chega a referir-se mesmo a Humboldt, erudito que, como o próprio Euclides (até então), jamais pisara as terras do sertão baiano.

Talvez por tomar como referencial para seu estudo textos de "viajantes", no sentido mais próprio de indivíduos em trânsito, de passagem, todos os três quartos iniciais do texto referem-se às características extremadas do regime climático da região como se ninguém ali estivesse fixado. Escreve o autor, acompanhando de perto a perspectiva de Saint-Hilaire:

E sobre as chapadas desertas e desoladas alevantam-se quase que exclusivamente os mandacarus (cereus) silentes e majestosos; árvores providenciais em cujos galhos e raizes armazenam-se os últimos recursos para a satisfação da sede e da fome ao viajante retardatário... (163)

Note-se que as chapadas são dadas como "desertas e desoladas", territórios por onde só podiam circular "viajantes retardatários". Ainda que, mais adiante, utilizando as palavras de outro estudioso para descrever o extremo oposto das condições geo-climatológicas da área, seja feita referência ao habitante do lugar, "sertanejo", a imagem predominante em toda essa seção do trabalho é a de uma região quase inteiramente desconhecida da civilização. $E$, dessa maneira, como que desprovida de habitantes regulares. Mesmo na porção final do texto, quando se refere aos "rudes sertanejos" do lugar, a construção utilizada pelo autor é significativa:

É sobre estes tabuleiros, recortados por inúmeros vales de erosão, que se agitam nos tempos de paz e durante as estaçōes das águas, na azáfama ruidosa e álacre da vaquejadas os rudes sertanejos [...] esses nossos patrícios de tipo etnologicamente indefinido, ainda, refletem naturalmente toda a inconstância $\mathrm{e}$ toda a rudeza do meio em que se agitam. (166-67)

O habitante da região, cuja conformação tipológica é dada como reflexo do meio, aparece não como elemento fixado na terra, habitando um território, 
na acepção primeira da palavra. É descrito como figura "inconstante", que "se agita" naquelas paragens.

Chega a parecer paradoxal essa caracterização, na medida em que, no mesmo fragmento, tal como acontecerá no artigo seguinte, e mais tarde n' $O s$ sertōes, o autor afirma o alto grau de identidade entre o homem e o meio naquele espaço. Contudo, essa é talvez a própria solução do paradoxo: identificando o sertanejo a "toda a inconstância e toda a rudeza do meio", Euclides da Cunha parece excluir do habitante da região seus traços mais caracteristicamente humanos. Ser humano, do ângulo letrado do autor, corresponderia a inserir-se no plano de uma civilização "mapeada", vale dizer, escrita. É de notar que, em sua descrição, Euclides desenvolve em paralelo as idéias da indefinição do tipo etnológico daquela gente, sua inconstância de temperamento e da instabilidade do ambiente físico.

Os sertanejos de Canudos tinham sido "educados numa rude escola de dificuldades e perigos", as condições de seu meio. Uma educação sem palavras.

\section{Nossos rudes compatriotas}

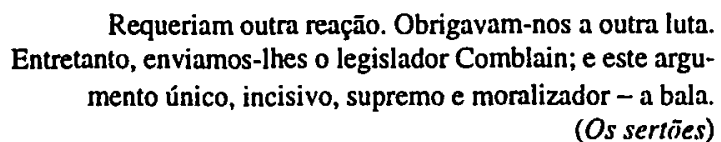

Merece atenção o modo de o autor caracterizar a )gente de Antonio Conselheiro. Suas referências aos defensores de Canudos não são de todo negativas, como na maioria dos textos jornalísticos sobre a guerra após o fracasso da terceira expedição. Apesar de tratá-los, de saída, como "horda dos fanatizados sequazes de Antonio Conselheiro" (161), ao final, o articulista a eles se refere como "nossos patrícios do sertão" (166), dotados de "almas ingênuas e simples" (167). Comentando sua resistência ao meio adverso, posta agora a serviço da defesa do arraial, Euclides fala de sua "coragem bárbara e singular", "heroísmo mórbido", e os compara aos "heróis intangíveis" da Vendéia. São "bárbaros" sim, mas singularmente corajosos em sua barbárie; são "mórbidos" 
em sua devoção ao líder messiânico, mas heróicos nessa morbidez. Coragem e heroísmo são, sem dúvida, traços tidos em alta conta por uma mentalidade afeita às coisas militares como a de Euclides da Cunha. Pode-se argumentar que enaltecer desse modo ambivalente a bravura do adversário não passasse de uma estratégia retórica para amenizar a dimensão dos fracassos das tropas republicanas. Contudo, uma expressão possui força inequivoca nessa caracterização: "nossos patrícios do sertão".

Embora reconhecendo nos defensores de Canudos adversários da República, Euclides da Cunha parece aceitar a gente de Conselheiro como parte de um frustrado projeto de Nação. Gente rude, mas de bom espírito; bárbara, mas corajosa; mórbida, mas heróica. O uso do pronome inclusivo, "nossos", é decisivo. Num momento em que o tom geral oscilava entre o pânico e a exaltação vingativa, a posição do autor é singular. Reafirma a perspectiva de um projeto de sociedade capaz de incorporar diferenças e distâncias.

É bem verdade que o artigo repisa a hipótese, então corrente, da manipulação dos sertanejos pelos "propagandistas do império", o que já se prefigura no título do artigo. E no seu fecho vem a afirmaçāo resoluta da confiança do autor em que "a República sairá triunfante desta última prova" (167). Entretanto, abrindo espaço, mesmo que de modo discreto, para a incorporação dos sertanejos ao quadro da Nação, Euclides da Cunha deixa entrever aquilo que constituiria o centro de sua indignação em face da experiência direta do conflito n'Os sertões:

Toda aquela campanha seria um crime inútil e bárbaro, se nāo se aproveitassem os caminhos abertos à artilharia para uma propaganda tenaz e persistente, visando trazer para o nosso tempo $\mathrm{e}$ incorporar à nossa existência aqueles rudes compatriotas retardatários. (490)

\section{Tênue verniz de cultura}

A rua do Ouvidor valia por um desvio das caatingas.

(Os sertōes) 
No segundo artigo, cresce a animosidade contra os conselheiristas. Escrito em meados de julho de 1897, quando eram grandes as críticas da opinião pública contra a morosidade das tropas e a continuidade da guerra, Euclides dedica a maior parte do texto à análise de questões de estratégia militar. Em sua caracterização do jagunço, termo usado ali pela primeira vez pelo autor, ainda em grifo, lança mão de um recurso estilístico que dominará seus demais escritos sobre o tema, e sobremaneira OS sertões: a antítese. Veja-se, por exemplo: "[sua] força está na própria inconsistência", "[suas] vantagens estão na própria inferioridade", "desbaratados hoje, revivem amanhã, dos próprios destroços, como pólipos" (170). Não deixa de ser digna de nota a aproximação final dos jagunços do semi-árido nordestino a pólipos: literalmente, colônias de organismos essencialmente aquáticos, em si mesma uma antítese (involuntária?) a mais.

Em certos trechos desse segundo artigo, a descrição dos perigos aos quais se submetem as tropas governamentais tem acentos góticos ${ }^{8}$ :

Caindo inopinadamente numa emboscada, ao atravessarem uma garganta estreita ou um capão de mato, os batalhões sentem a morte rarear-lhes as fileiras e não vêm o inimigo-fulminando-os do recesso das brenhas ou abrigados pelos imensos blocos de granito que dão a certos trechos daquelas paragens uma feição pitoresca e bizarra, amontoado no alto dos cerros alcantilados, como formas evanescentes de antigas fortalezas derruídas... (p. 172).

Este traço acentua-se pelo paralelo, logo a seguir, entre o sertanejo e o "iluminado da Idade Média" (173). Esse elemento medievalizante da caracterização da região seria retomado e acentuado em suas conseqüências críticas na abertura d'Os sertões, quando o autor confessa, na Nota Preliminar, que a "campanha [de Canudos] lembra um refluxo para o passado" (86).

8 Já no primeiro artigo, certos traços de descrição da paisagem tem um tom algo fantasmagórico, como os mandacarus de "conformação típica e bizarra como grandes candelabros firmados sobre o solo" (163); ou as imupçōes graníticas que se elevam "largamente fendida[s] em direçōes quase perpendiculares, dando a ilusāo de lanços colossais e semi-derruídos de ciclópica muralha" (165-66); ou ainda a comparação dessas formaçōes rochosas aos "dólmens da Bretanha". Note-se que, ponto por ponto, as alusões a elementos de tradição européia para a descrição do cenário natural do sertão nordestino compara objetos resultantes da intervençāo humana, as "muralhas" e os "dólmens", a acidentes decorrentes da ação da natureza. 
Outro traço singular do segundo artigo está no fato de Euclides utilizar copiosos exemplos de guerras coloniais. Refere-se à "Inglaterra enfrentando os zulus e afegãos, a França em Madagascar e [a] Itália ... com os abissínios" (169); alude ainda à luta de Cuba contra a Espanha, após mencionar as dificuldades do exército de Napoleão para submeter a própria Espanha, décadas antes (172-73). O autor tenta sublinhar a situação temporariamente difícil por que tropas regulares, em vantagem material e numérica, passaram em embates contra inimigos mais "primitivos", conhecedores exímios, porém, do cenário dos combates e atuando em estratégia de "guerrilha". O traço duramente irônico que escapa ao articulista reside em ele, filho de uma ex-colônia européia, posicionarse ao lado das metrópoles, contra seus "patrícios". Ao contrário dos europeus e anglo-saxões em geral, para quem os bárbaros representavam o outro, o adversário, o colonizado, os que estavam do lado de fora, no texto de Euclides da Cunha, bárbaros eram os que estavam do lado de dentro. Nossos bárbaros éramos nós mesmos.

A seção final do segundo artigo abre-se com uma consideração elogiosa a respeito da marcha das colunas republicanas em direção a Canudos. Vale a pena reter a oposição entre a idéia da "marcha do exército nacional" (173) e "a tática de fuga" dos jagunços (169). Nos dois últimos parágrafos do texto, Euclides alude às estradas romanas, memória perene da solidez e ordem militar de uma civilização. Fica claro que, para o autor, a guerra teria aí o sentido de uma ação civilizatória. Compreensível num espírito que ainda não tivera contacto direto com os horrores de uma guerra verdadeira, muito menos de um conflito intestino como o de Canudos, o parágrafo que lhe segue, fechando o texto, lança uma perturbadora consideração:

Mas, amanhã, quando forem desbaratadas as hostes fanáticas do Conselheiro e descer a primitiva quietude sobre os sertões baianos, ninguém conseguirá perceber, talvez, através das matas impenetráveis, coleando pelo fundo dos vales, derivando pelas escarpas íngrimes das serras, os trilhos, as veredas estreitas por onde passam, nesta hora, admiráveis de bravura e abnegaçāo os soldados da República. (175-76)

Há uma certa sensação de incongruência, que parece vir do contraste entre o elogio patriótico que fecha o parágrafo e seu desenvolvimento geral. Existe um misto de melancolia e desalento na afirmação de que, quando terminassem os combates e se restabelecesse a "primitiva calma", não restariam traços da missão civilizadora levada a cabo pelos soldados. Em outras palavras, sub- 
metido pela força das armas, o sertão permaneceria irredutivel em sua quietude "primitiva", impenetrável, como sua vegetação rala e trançada, à marcha da civilização.

De alguma maneira, os conselheiristas parecem incomodar a Euclides da Cunha por terem "ocupado" um recanto do Brasil antes de os intelectuais terem podido dele "se ocupar". É como se cientistas e fanáticos estivessem disputando um território completamente ignorado e, portanto, originalmente vazio. Substituídos os jagunços pelos soldados, instrumentos da marcha civilizatória, o resultado seria o retorno da região à sua condição anterior de quietude. A inútil e desoladora paz de um deserto.

Elemento interessante a esclarecer a diferença de tom no tratamento dado aos conselheiristas nos dois artigos é a circunstância de o primeiro ter sido escrito no momento em que o grupo florianista, que tinha em Moreira César uma de suas derradeiras lideranças, ter sofrido duro revés, enquanto o segundo se produz no ápice das críticas às ações da quarta expedição, organizada sob as ordens do próprio Marechal Bittencourt, Ministro da Guerra e homem forte da corrente civilista nas Forças Armadas. O autor era adversário do primeiro, e simpatizante do segundo grupo. Apesar de militar de formação e republicano exaltado, Euclides da Cunha já passara por duros momentos durante o governo de Floriano Peixoto, que acabaram por conduzi-lo à reforma voluntária em 1895. Não é irrelevante a influência desses fatos na diferença de tratamento antes mencionada. De fato, a própria estratégia retórica equilibrada, bem como a escassez relativa de referências diretas aos combates, dão conta, desde logo, de uma percepção do conflito de Canudos no quadro mais amplo das disputas políticas nacionais. Não nos termos exclusivamente redutores de um "movimento restaurador", mas no quadro maior que opunha os grupos jacobinos e os militares exaltados ao núcleo civil da República.

Assim, nesses dois artigos anteriores à experiência direta da guerra, Euclides da Cunha deixa entrever diferentes aspectos que se cristalizariam na feitura d'Os sertões: do ângulo retórico, já se observa um plano geral que parte do reconhecimento do meio natural para a determinação do elemento humano, e daí à crônica do combate; está presente, desde logo, a ambivalência com que se caracteriza o habitante do lugar, a profusão de referências aos relatos de naturalistas sobre a região; do ângulo das idéias, já é possível identificar traços da convicção do autor quanto à necessidade de incorporar-se à nacionalidade aqueles adversários apenas momentâneos do sertão; por fim, pode-se ler na ambígua melancolia com que o autor encerra o segundo artigo a ponta de um lamento antecipado pela inocuidade da ação civilizatória daquela campanha militar. 


\title{
Crianças, cabeças e chapéus
}

\begin{abstract}
O nome de Antonio Conselheiro acabará por entrar na memória desta mulher anônima, e não sairá mais. Ela levava uma pequena, naturalmente filha; um dia contará a história à filha, depois à neta, à porta da estalagem, ou no quarto em que residirem. (Machado de Assis, crônica de 14/02/97)
\end{abstract}

Com o título "Há um século o Brasil afunda em Canudos", Antônio Callado publicou em abril de 1996 uma crônica ${ }^{9}$ onde misturavam-se três temas perfeitamente articuláveis: o centenário da guerra, o lançamento de um álbum fotográfico sobre a região dos conflitos e um artigo de Sérgio Paulo Rouanet com uma interpretação dos episódios. Deste último, Callado extrai a menção a duas outras crônicas relacionadas ao tema: aquela de Machado de Assis, citada no início do presente artigo; e uma outra, de Euclides da Cunha, escrita em 1908, quando da morte do escritor.

Lembrando que a região onde um dia fora instalada a comunidade liderada por Antonio Conselheiro e fora travada nossa mais sangrenta guerra civil transformara-se em um açude, Callado assinala com melancolia a persistência das condições de desequilíbrio e injustiça que Canudos emblematizara havia cem anos. Dialogando de modo enviesado com o texto machadiano, o cronista contemporâneo cumpria a dolorosa missão de "celebrar" o centenário daquele episódio, lançando-se em retrospectiva e refletindo especularmente a expressão de Machado para Canudos, "episódio que não tem nada fim-de-século", na forma dos séculos sem fim de um "Brasil trágico que não acaba nunca".

Na conclusão da crônica machadiana, o tema do centenário da cartola combina-se aos demais nos seguintes termos:

Tem-se dito muito mal deste chapéu. Chamam-lhe cartola, chaminé, e nāo tarda canudo, para rebaixá-lo até a cabeleira

9 Folha de S. Paulo, 20/04/96, cad. 4, p. 8. 
hirsuta de Antonio Conselheiro. No Carnaval, muita gente não o tolera, e os mais audazes saem à rua de chapéu baixo, não tanto para poupar o alto, como para resguardar a cabeça, sem a qual nāo há chapéu alto nem baixo. (418)

É notável o paralelo entre hábitos civilizados e arcaicos, cidade e sertão, que se pode extrair deste comentário. E se lembrarmos que, além da prática generalizada da degola dos prisioneiros pelas tropas oficiais, o próprio cadáver do Conselheiro foi exumado e decapitado no desfecho dos combates, as palavras de Machado ganham um caráter involuntariamente profético.

Mas a crônica de Euclides da Cunha sobre a morte do autor do Memorial de Aires também se fecha de modo significativo. Lamentando a escassa assistência popular aos últimos instantes do grande escritor, o cronista alegra-se ao ver um menino aproximar-se para despedir-se do mestre e sentencia: "Pelos nossos olhos passara a impressão visual da Posteridade".

$O$ episódio remete quase que de modo direto a uma passagem d' $O s$ sertões. Após descrever um menino de nove anos que fora feito prisioneiro e impressionava a todos por sua desenvoltura no trato com as armas e a crueza da luta, escrevera:

Aquela criança era, por certo, um aleijão estupendo. Mas um ensinamento. Repontava, bandido feito, a tona da luta, tendo sobre os ombros pequeninos um legado formidável de erros. Nove anos de vida em que se adensavam três séculos de barbárie. (480)

Entre a criança prisioneira de Canudos, herdeira de séculos de barbárie, e o menino ao pé do leito de morte machadiano, seta apontando para uma hipotética redenção futura de nossa cultura e nossa sociedade, estendiam-se, dilaceradamente, as esperanças de Euclides da Cunha.

No fecho amargurado da crônica de Antonio Callado, o escritor confessa:

Aqui entre nós, acho que Euclides tinha querido encontrar cercando Laranjeiras, o Rio, e indo até a rua do Ouvidor, rudes homens de sandália, rolando nas mãos os chapéus de palha. $O$ menino a quem Euclides chamou, não sem alguma arrogância, Posteridade, em breve estaria enterrado também. O que ali ficara faltando era o seu Brasil trágico, que não acaba nunca. 
Os dois meninos, de Canudos e da Capital, estão mortos. Os três cronistas também. E a relíquia que deles todos perdura, é a consciência de mais um século de barbárie adensado sobre os ombros do país, afundando nas encruzilhadas das favelas e de tantos desvios do tempo. Sem o resguardo de qualquer chapéu com que possamos proteger nossas cabeças. A não ser, talvez, a sombra das palavras.

Curitiba, 14 de fevereiro de 1997

\section{RESUMO}

Discussão dos artigos "A nossa Vendéia" (1897), de Euclides da Cunha, de modo a identificar já nestes ensaios preliminares não apenas o plano geral da abordagem do conflito, mais tarde desenvolvida em Os sertöes, mas aspectos do desencanto com o projeto republicano e modernizador para a nossa sociedade. Essa leitura se faz emoldurada por duas crônicas sobre o episódio de Canudos, separadas entre si por um século, uma de Machado de Assis, escrita em fevereiro de 1897, e a outra de Antonio Callado, de 1996.

Palavras-chave: Guerra de Camudos, Euclides da Cunha, Machado de Assis.

\section{ABSTRACT}

This is a reading of "A nossa Vendéia" (1897), two articles by Euclides da Cunha, in which one may find some relevant elements that would be developed in Os sertöes (1902), both in the text structure and the criticism against the republican government. In addition, it considers two newspaper texts about Canudos War: one by Machado de Assis, written in 1897, and the other one by Antonio Callado in 1996. 